Geografia e Ordenamento do Território, Revista Eletrónica

Centro de Estudos de Geografia e Ordenamento do Território

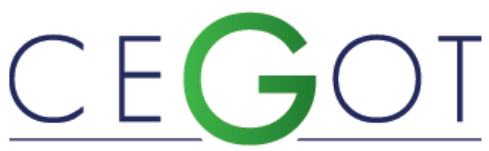

Centro de Estudos de Geografia e Ordenamento do Território

http://cegot.org

ISSN: 2182-1267

Souza, G.

Univesidade Federal do Amazonas

geraldoalves@ufam.edu.br

Leite, $\mathrm{A}$.

Universidade Federal do Rio de Janeiro

alinedmle@gmail.com

\title{
Análise da variação do tempo dedicado às viagens urbanas da população de Manaus - AM, em Função do modo de transporte utilizado
}

Referência: Souza, G. e Leite, A.. (2012). Análise da variação do tempo dedicado às viagens urbanas da população de manaus - AM, em Função do Modo de Transporte Utilizado. Revista de Geografia e Ordenamento do Território, n.ำ 1 (Junho). Centro de Estudos de Geografia e Ordenamento do Território. Pág. 85 a 102

\section{Resumo}

A ausência de planejamento, característica da maioria dos bairros de Manaus deixou como herança um sistema viário incompatível com o tamanho atual da cidade. Neste artigo busca-se analisar a variação do tempo dedicado às viagens urbanas em Manaus em função de três diferentes modos de transporte: ônibus, micro-ônibus e automóvel. Receptores do Sistema de Posicionamento Global (GPS) e recursos de um Sistema de Informações Geográficas (SIG) foram utilizados para levantar e tratar os dados das 
viagens urbanas realizadas. Considera-se (por tudo o que o trabalho permitiu concluir), que a metodologia adotada foi bastante consistente para o reconhecimento da variação de desempenho de modos de transporte investigados. Os percursos mais longos permitiram melhor desempenho que os mais curtos, notadamente influenciado pela área central da cidade, que registrou os trechos mais lentos para os três modos.

Palavras-Chave: Manaus, Mobilidade Urbana, GPS, SIG.

\begin{abstract}
The lack of planning, characteristic of most of the neighborhoods of Manaus bequeathed a road system incompatible with the current size of the city. This article seeks to analyze the variation of time devoted to travel in urban Manaus according to three different modes of transport: buses, minibuses and cars. Receivers Global Positioning System (GPS) and features a Geographic Information System (GIS) were used to raise and process the data of urban trips made. It is considered (for all that work concluded) that the methodology was fairly consistent for the recognition of the performance variation of the modal investigated. The paths longer allowed better performance than shorter ones, notably influenced by the central city area, which recorded the slowest stretches for the three modes.
\end{abstract}

Keywords: Manaus, Urban Mobility, GPS, GIS. 


\section{Introdução}

Desde os anos cinqüenta do século passado o processo de urbanização ocorrido do Brasil causou um crescimento das cidades para além do necessário para abrigar a sua população. Ao mesmo tempo, registrou-se uma incapacidade do estado em disciplinar este crescimento urbano. Em conseqüência disso, boa parte do sítio urbano da maioria das cidades brasileiras acabou por ser formado sem observar princípios básicos de planejamento urbano, com impacto direto sobre a cidade como um todo e sobre o sistema viário em particular. Com o crescimento das cidades, os deslocamentos urbanos passaram a exercer forte influência sobre a qualidade de vida das pessoas, com um tempo cada vez maior sendo dedicado a estes deslocamentos.

Se antes as distâncias eram pequenas e vencidas a pé, a nova realidade exige meios de transporte motorizados. Pode-se dizer, por outro lado, que o processo de urbanização verificada no Brasil neste período é causa e conseqüência do desenvolvimento da indústria automobilística no país. Ao mesmo tempo em que este setor da economia absorvia boa parte da mão de obra emigrante do campo, ampliando o mercado de trabalho, a expansão das cidades acabou por justificar os investimentos na construção de pontes, viadutos, ruas e rodovias conjuntos habitacionais distantes da área central, infra-estrutura necessária para promover a expansão do mercado consumidor dos produtos destas indústrias.

O tempo ou distância de deslocamentos limitam o número de oportunidade às pessoas (Morris et al 1978 apud Goto, 2000). Dentre os vários problemas decorrentes da urbanização rápida e sem planejamento, merecem atenção os problemas relacionados ao transporte. Estes problemas podem levar à dificuldade de exercício um direito básico do cidadão, o direito de ir e vir. O acelerado processo de industrialização e urbanização do Brasil dos últimos sessenta anos deixou como herança para este início de século, cidades com um tecido urbano marcadamente desigual: bolsões de pobreza em distantes periferias e bairros de classe média e alta em áreas de melhor centralidade urbana. 
Para Souza (2010), o local de moradia na cidade exerce forte influência sobre as oportunidades de realizações pessoais e profissionais das pessoas. Mas ao que parece, este aspecto é pouco compreendido pela população de baixa renda, visto que se sujeitam fixar residências em locais muito distantes das áreas centrais, carente da presença do estado e com enormes desafios relacionados com a mobilidade urbana. As localizações são definidas pelas condições e possibilidades de acesso de cada indivíduo aos recursos do espaço urbano. Como conseqüência desse modelo de desenvolvimento urbano e de distribuição de renda, esta população tem uma absurda dependência dos meios de transporte público e um precioso tempo dedicado às viagens, impactando diretamente na sua qualificação profissional. Essas condições e possibilidades são por sua vez, determinadas pela organização social e pelos meios de transporte (Villaça, 2001).

Apesar de providas de escolas de nível básico, delegacias, Serviços de ProntoAtendimento a saúde (SPA), estes serviços, além de não ser suficientes em quantidade e qualidade para o atendimento desta população, boa parte das viagens urbanas destas populações destinam-se a outros bairros, relacionadas ao emprego, educação, lazer, etc. (Moura et al, 2010).

Este trabalho parte da hipótese de que o sistema viário da cidade (mal planejado) tem sido responsável por aumentar a duração das viagens urbanas dos moradores de Manaus. Considerou-se também que este impacto varia em função do modo de transporte que se utiliza, de tal modo que os usuários do transporte coletivo por ônibus convencional devem ser mais penalizados que as pessoas que utilizam o automóvel para as suas viagens urbanas.

\section{Evolução e Transporte Urbano em Manaus}

A partir do início da década de 1970 teve inicio a implantação de um pólo econômico incentivado em Manaus - a Zona Franca de Manaus. Como conseqüência disso a cidade passou a registrar elevados índices de crescimento urbano e demográfico, com forte impacto sobre o tecido urbano. A partir do início deste projeto, muitos bairros foram formados sem planejamento, trazendo à cidade vários problemas relacionados 
à mobilidade e acessibilidade de sua população. A cidade de Manaus (hoje com mais de um milhão e oitocentos mil habitantes - censo do IBGE, 2010), possui um sistema viário incompatível a sua dimensão espacial, com a frota de veículos e com a sua importância econômica atual. O mapa da figura 1 destaca as principais vias arteriais existentes atualmente na cidade.

Figura 1 - Principais eixos viários. Fonte: Base Cartográfica da PMM, 2009. Organização: Aline Leite, 2012.

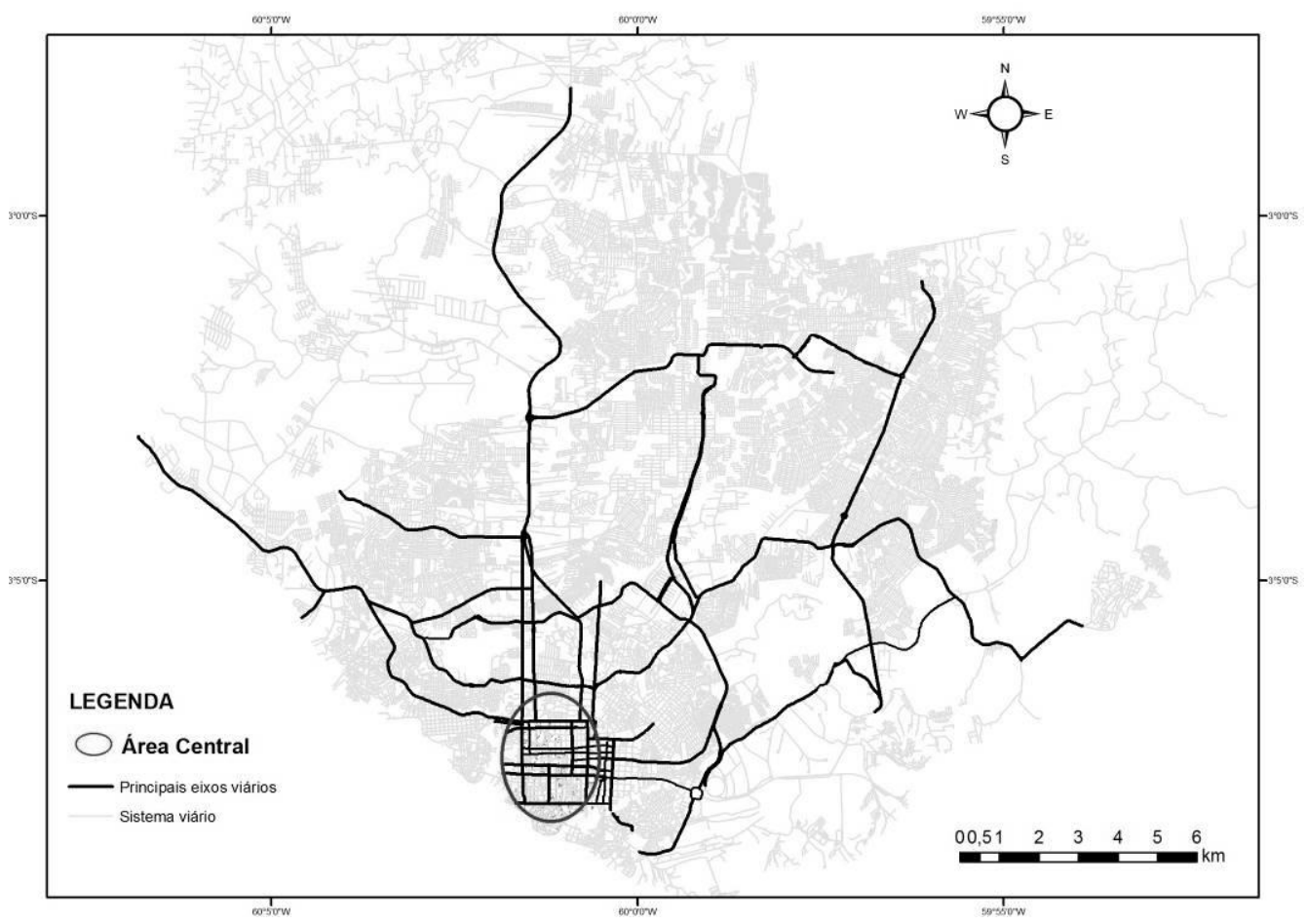

Como é possível notar, são bastante sinuosas e há poucas vias paralelas. Uma das conseqüências deste modelo é a escassez de alternativas tanto para o transporte público quanto para o particular. Em função disso os congestionamentos de trânsito estão se tornando cada vez mais presentes no dia a dia da cidade.

Para Nogueira et al (2007) o crescimento demográfico na cidade de Manaus pode ser dividido em duas fases. A primeira que vai até a década de 1970 em que as áreas de ocupação estavam concentradas nas zonas administrativas sul, centro sul, leste e centro oeste. Neste período as margens dos igarapés da cidade eram densamente povoadas. E a segunda ocorreu com a implantação da Zona Franca de Manaus que possuía um papel polarizador, pois com sua implantação ocorreu um constante fluxos migratórios de pessoas atraídas pela oportunidade de emprego que ela oferecia. Com 
isso, no final da década de 1970 começa a expansão para as zonas administrativa Leste e Norte por ocupações regulares e irregulares.

Com acelerado crescimento demográfico de Manaus a cidade sofreu ampliação espacial, e o processo de ocupação foi seguindo a morfologia do terreno: áreas mais centrais e melhor dotadas de equipamentos urbanos foram ocupadas preferencialmente por população de melhor poder aquisitivo, ao mesmo tempo em que confinavam as populações mais carentes na periferia da grande cidade. Para aumentar a complexidade do tecido urbano, condomínios de luxo são estabelecidos em pontos longínquos da periferia para desfrutar das amenidades proporcionadas pelo espaço quase rural e terrenos impróprios para edificações, tais como os fundos de vales (alagáveis em períodos de cheias), localizados em áreas mais centrais foram sendo apropriados por populações mais pobres.

O transporte coletivo de Manaus teve início ainda na época do ciclo da borracha, quando residências foram sendo fixadas depois dos igarapés que cercam a área central, dando origem aos bairros de Educandos e São Raimundo. Em função da ausência de pontes, para a realização das travessias foram utilizadas catraia pequenas canoas movidas a remo. Ainda neste período foi implantado um sistema de transporte sobre trilhos - o bonde de Manaus. Com a recessão econômica que dominou a economia do estado após o ciclo da borracha, muito dos empreendimentos sofreram descontinuação, sendo o bonde um deles. Com a recuperação da economia e do crescimento da cidade, impulsionadas pela ZFM, um serviço de transporte coletivo urbano passou a ser oferecido. A administração municipal criou, no inicio da década de 1980 a Empresa Municipal de Transporte Urbano - EMTU, responsável pelo transporte coletivo urbano. Este é prestado pela iniciativa privada sob concessão pública, utilizando ônibus convencionais. Mais recentemente alguns ônibus articulados e bi-articulados foram introduzidos no sistema.

O sistema de transporte coletivo de Manaus utiliza ônibus urbano e este serviço é prestado por empresas privadas, sob concessão do órgão municipal de trânsito, atualmente denominado. Esta instituição foi criada no início da década de 1980 e é responsável pelo gerenciamento e fiscalização do transporte coletivo de Manaus. 0 transporte coletivo conta atualmente com cinco terminais destinados à integração 
física e tarifária. Não obstante a existência destes terminais, um percentual muito grande das linhas de ônibus é do tipo radial, ligando os bairros ao centro da cidade (Souza, 2010).

Uma das conseqüências da ausência de planejamento urbano é o crescimento da mancha urbana, de modo desnecessário. Nos últimos quarenta anos a mancha urbana de Manaus cresceu proporcionalmente bem mais que a população da cidade, fazendo cair a densidade demográfica e aumentando a extensão das viagens urbanas. 0 transporte público não tem conseguido atender a demanda da população com qualidade adequada. Em função disso surgiram operadores não credenciados pelo poder concedente, conhecidos como clandestinos. Inicialmente este serviço ficou restrito à zona leste, mas atualmente atua em toda a cidade. Mais recentemente surgiu o serviço de transporte de passageiros urbanos prestados por motos conhecido como moto táxi. A cidade também registra, em certas áreas da cidade, principalmente em mais próximos do centro o serviço conhecido como táxi-lotação. Estas alterações no sistema de transporte urbano encarecem o sistema oficial, refletindo diretamente na tarifa autorizada pelo poder público.

Os investimentos públicos feitos na expansão e adequação do sistema viário não têm sido suficiente para resolver os problemas de fluidez no trânsito, cada vez mais comum na cidade. Desde a década de 1990 que a cidade passou a enfrentar congestionamentos de trânsito. Com o acentuado crescimento da frota de veículos particulares registrado desde então, as condições de circulação tem piorado a cada ano que passa.

O Pólo Industrial de Manaus - PIM, principal motor da economia do Estado, está situado a leste da área central da cidade, e atualmente é responsável por mais de cem mil empregos diretos, Os bairros residenciais situam-se a norte e a oeste deste. Mais de setenta por cento deste quadro de trabalhadores é transportado por ônibus, mas eles não utilizam o sistema de transporte coletivo urbano da cidade. As indústrias do PIM contratam empresas para prestarem o serviço de transporte de seus funcionários. Assim, os ônibus fretados desenvolvem itinerários específicos ligando as residências às fábricas. Diariamente são utilizados mais de 500 ônibus para este sistema de transporte em Manaus (Leite e Souza, 2011). 


\subsection{Vias arteriais não construídas}

Segundo a Prefeitura de Manaus e CEFTRU (2006), nos anos 80, a população concentrava-se no centro da cidade. Havia um eixo norte-sul de deslocamento bem demarcado Taco et al (2008). A cidade se expandia paralelamente ao rio Negro, em direção ao Distrito Industrial. No final dos anos 1980 e começo dos anos 1990, o crescimento populacional em direção norte, leste e nordeste foi muito acentuado (Oliveira, 2002). Estas regiões eram as de menor resistência à expansão, apresentando maior disponibilidade de terrenos e maior facilidade de acesso viário em direção ao centro da cidade.

A região central, a região do porto e o distrito industrial já se mostravam consolidados, enquanto dezenas de empreendimentos habitacionais eram construídos nas regiões Norte e Leste. Já no final dos anos 1990 as regiões Norte e Leste encontravam-se consolidadas, sendo as zonas de maior crescimento em Manaus. A zona norte já apresentava aproximadamente 150 mil habitantes e a zona leste aproximadamente 230 mil habitantes. A partir do ano 2000 intensificou-se a expansão na direção oeste, paralelamente ao Rio Negro. A classe média e média alta se deslocou para a Ponta Negra, que recebeu uma quantidade grande de empreendimentos habitacionais para população de alta renda (Moura, 2010). Nota-se, pois que o transporte tem uma função na organização e estruturação do espaço e dos territórios, que podem variar segundo o nível de desenvolvimento.

Taco et al (2008) fizeram um estudo acerca das diferentes escalas de análise de índice de acessibilidade com base em padrões pontuais e áreas da cidade de Manaus, ou seja, quais as zonas e áreas dessas zonas são mais acessíveis. O trabalho verificou que as Zonas consideradas mais acessíveis, situam-se na parte leste do município e na parte sudoeste do mesmo. Em comparação com os índices e estudos anteriores, observa-se que o centro geográfico da cidade, o centro tradicional situa-se em uma área considerada pouco acessível.

Nota-se que os desafios enfrentados pela população de Manaus em seus deslocamentos diários não têm sido poucos. Sistemas que concorrem entre si, o Distrito Industrial com sistema próprio de transporte de seus operários, uma frota de 
veículos particulares crescendo em ritmo acelerado e congestionamentos de trânsito. Sejam os usuários do transporte fretado, do transporte público e até mesmo os de veículos particulares, os tempos dedicados às viagens urbanas em Manaus é cada vez maior.

\section{Metodologia}

Segundo dados da Superintendência Municipal de Transportes Urbanos - SMTU, cerca de 90 linhas de ônibus de transporte coletivo, de diversas áreas da cidade passam pela Avenida Epaminondas, localizada no centro de Manaus. Tomando um ponto de ônibus localizado nesta avenida, buscou-se identificar destinos em diferentes bairros da cidade que contasse com o transporte por ônibus convencional e micro-ônibus para o reconhecimento de itinerários percorridos e o desempenho de cada um dos três modos pesquisados.

Partindo deste ponto por volta de 17 horas (horário de pico), três usuários embarcaram (cada um em um tipo de veículo) para chegarem ao mesmo destino. Utilizando aparelhos GPS foram coletando pontos ao longo do percurso. Depois que os três usuários chegaram ao destino, o mesmo percurso foi feito com destino ao ponto de onde partiram, no centro da cidade (horário de vale). Foram realizados dez percursos no sentido bairro e no sentido centro, totalizando vinte percursos. O tipo de aparelho utilizado permitiu coletar, além das coordenadas geográficas, o horário exato onde cada veículo se encontrava quando os pontos foram marcados. A pesquisa levantou também o tempo de espera pelo modo de transporte e os custos de cada um destes.

Considerando-se que o modo de dirigir de um motorista (mais agressivo ou mais conservador) influencia no resultado final das viagens, decidiu-se utilizar o serviço de táxi da cidade para aferir o desempenho do automóvel. Como um usuário qualquer que sai à rua e espera pela passagem de um taxi ou de quem liga para a central solicitando o serviço de um, o pesquisador embarcava no táxi e informava apenas o destino da viagem; não o motivo. 
Os dados levantados em campo foram extraídos dos aparelhos GPS e importados para um ambiente de Sistema de Informações Geográficas - SIG (figura 02). Neste ambiente foi possível traçar os trajetos percorridos pelos modos e reconhecer variações na velocidade das viagens para cada modo pesquisado.

Figura 02 - Principais eixos viários. Fonte: Base Cartográfica da PMM, 2009. Organização: Aline Leite, 2012.

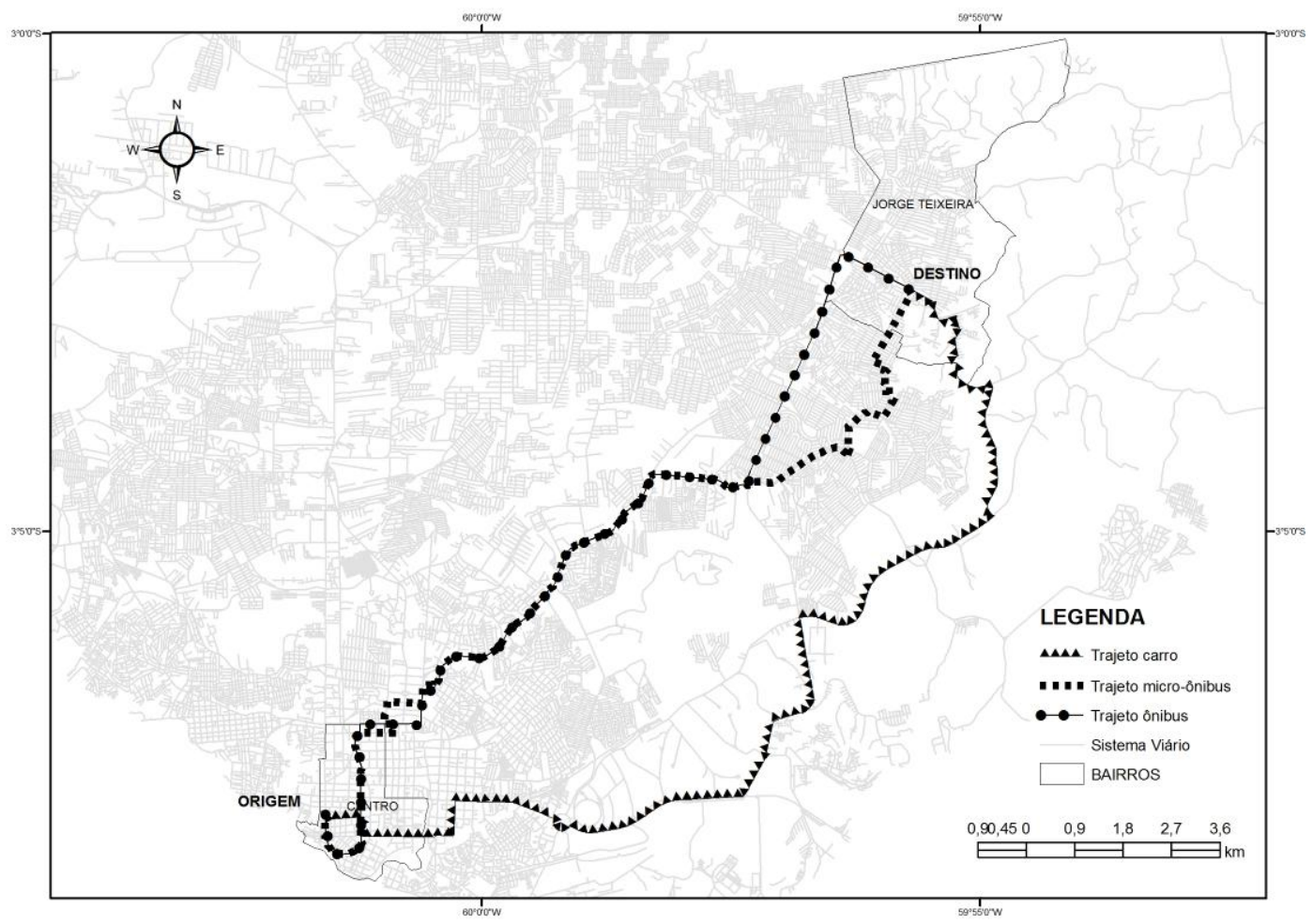

Tem-se (a título de ilustração) na figura 2 os itinerários de um dos levantamentos realizados no sentido centro - bairro. Como é possível notar, o percurso do automóvel é bastante diferente dos outros dois modos.

Um Sistema de Informações Geográficas - SIG (e outros recursos de informática) foi utilizado para reconhecer os itinerários percorridos por cada veículo, a velocidade média de trechos das viagens e a velocidade média final. Utilizou-se uma base cartográfica para reconhecer as vias percorridas por cada um dos veículos.

\section{Resultados e Discussão}

Como dito anteriormente, os percursos realizados em direção aos bairros partiram em horário de pico, com vários trechos de Manaus enfrentando congestionamentos de 
trânsito. Já os percursos de retorno ao centro seguiram no contra-fluxo do trânsito. Em função disso é de se esperar que a velocidade média das viagens de volta ao centro apresente velocidade média superior às que seguiram para os bairros. Os dados confirmaram isso (tabela 1).

Tabela 01: Bairros de Manaus para os quais se realizou trajetos para a pesquisa.

\begin{tabular}{|c|c|c|c|c|c|}
\hline & DESTINO & MODO & TEMPO [min] & EXTENSÃO [km] & VEL. MÉDIA [km/h] \\
\hline \multirow{6}{*}{ 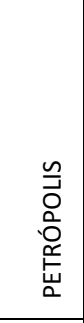 } & \multirow{3}{*}{ BAIRRO } & Carro & 53 & 8,1 & 9,2 \\
\hline & & Micro-ônibus & 38 & 8,0 & 12,6 \\
\hline & & Ônibus & 46 & 8,1 & 10,6 \\
\hline & \multirow{3}{*}{ CENTRO } & Carro & 31 & 6,4 & 12,4 \\
\hline & & Micro-ônibus & 31 & 6,6 & 12,8 \\
\hline & & Ônibus & 40 & 7,0 & 10,5 \\
\hline \multirow{6}{*}{ 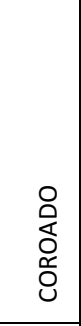 } & \multirow{3}{*}{ BAIRRO } & Carro & 45 & 7,3 & 9,7 \\
\hline & & Micro-ônibus & 50 & 10,3 & 12,4 \\
\hline & & Ônibus & 67 & 8,0 & 7,2 \\
\hline & \multirow{3}{*}{ CENTRO } & Carro & 19 & 7,1 & 22,4 \\
\hline & & Micro-ônibus & 27 & 7,1 & 15,8 \\
\hline & & Ônibus & 26 & 7,1 & 16,4 \\
\hline \multirow{6}{*}{ 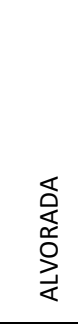 } & \multirow{3}{*}{ BAIRRO } & Carro & 45 & 9,0 & 12,0 \\
\hline & & Micro-ônibus & 56 & 9,7 & 10,4 \\
\hline & & Ônibus & 54 & 9,7 & 10,8 \\
\hline & \multirow{3}{*}{ CENTRO } & Carro & 21 & 6,6 & 18,9 \\
\hline & & Micro-ônibus & 29 & 9,6 & 19,9 \\
\hline & & Ônibus & 38 & 10,2 & 16,1 \\
\hline \multirow{6}{*}{  } & \multirow{3}{*}{ BAIRRO } & Carro & 61 & 9,3 & 9,1 \\
\hline & & Micro-ônibus & 61 & 12,5 & 12,3 \\
\hline & & Ônibus & 61 & 10,6 & 10,4 \\
\hline & \multirow{3}{*}{ CENTRO } & Carro & 31 & 8,6 & 16,6 \\
\hline & & Micro-ônibus & 34 & 10,7 & 18,9 \\
\hline & & Ônibus & 38 & 8,9 & 14,1 \\
\hline \multirow{6}{*}{ 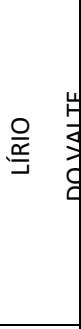 } & \multirow{3}{*}{ BAIRRO } & Carro & 41 & 11,6 & 17,0 \\
\hline & & Micro-ônibus & 58 & 12,8 & 13,2 \\
\hline & & Ônibus & 56 & 13,8 & 14,8 \\
\hline & \multirow{3}{*}{ CENTRO } & Carro & 25 & 10,9 & 26,2 \\
\hline & & Micro-ônibus & 44 & 13,0 & 17,7 \\
\hline & & Ônibus & 57 & 13,6 & 14,3 \\
\hline \multirow{5}{*}{$\begin{array}{l}\text { O } \\
\sum \\
\sum \\
\Sigma\end{array}$} & \multirow{3}{*}{ BAIRRO } & Carro & 36 & 13,4 & 22,3 \\
\hline & & Micro-ônibus & 52 & 13,7 & 15,8 \\
\hline & & Ônibus & 68 & 14,0 & 12,4 \\
\hline & \multirow{2}{*}{ CENTRO } & Carro & 19 & 12,3 & 38,8 \\
\hline & & Micro-ônibus & 24 & 12,8 & 32,0 \\
\hline
\end{tabular}




\begin{tabular}{|c|c|c|c|c|c|}
\hline & & Ônibus & 37 & 12,9 & 20,9 \\
\hline \multirow{6}{*}{ 足 } & \multirow{3}{*}{ BAIRRO } & Carro & 61 & 14,0 & 13,8 \\
\hline & & Micro-ônibus & 73 & 16,7 & 13,7 \\
\hline & & Ônibus & 84 & 16,0 & 11,4 \\
\hline & \multirow{3}{*}{ CENTRO } & Carro & 31 & 13,7 & 26,5 \\
\hline & & Micro-ônibus & 47 & 15,7 & 20,0 \\
\hline & & Ônibus & 37 & 15,4 & 25,0 \\
\hline \multirow{6}{*}{ 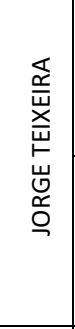 } & \multirow{3}{*}{ BAIRRO } & Carro & 53 & 21,4 & 24,2 \\
\hline & & Micro-ônibus & 48 & 18,2 & 22,8 \\
\hline & & Ônibus & 117 & 18,0 & 9,2 \\
\hline & \multirow{3}{*}{ CENTRO } & Carro & 66 & 17,8 & 16,2 \\
\hline & & Micro-ônibus & 42 & 16,4 & 23,4 \\
\hline & & Ônibus & 46 & 17,3 & 22,6 \\
\hline \multirow{6}{*}{ 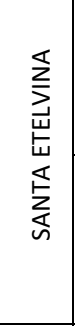 } & \multirow{3}{*}{ BAIRRO } & Carro & 63 & 19,1 & 18,2 \\
\hline & & Micro-ônibus & 97 & 21,1 & 13,1 \\
\hline & & Ônibus & 84 & 19,2 & 13,7 \\
\hline & \multirow{3}{*}{ CENTRO } & Carro & 26 & 18,4 & 42,5 \\
\hline & & Micro-ônibus & 39 & 19,1 & 29,4 \\
\hline & & Ônibus & 30 & 17,3 & 34,6 \\
\hline \multirow{6}{*}{$\begin{array}{ll}4 & 4 \\
2 & 4 \\
2 & 4\end{array}$} & \multirow{3}{*}{ BAIRRO } & Carro & 70 & 22,6 & 19,4 \\
\hline & & Micro-ônibus & 84 & 20,1 & 14,4 \\
\hline & & Ônibus & 82 & 20,7 & 15,1 \\
\hline & \multirow{3}{*}{ CENTRO } & Carro & 39 & 19,7 & 30,3 \\
\hline & & Micro-ônibus & 39 & 19,1 & 29,4 \\
\hline & & Ônibus & 40 & 17,2 & 25,8 \\
\hline
\end{tabular}

Na tabela 2 apresenta-se a variação de desempenho por modo e por sentido.

Tabela 2: Média das velocidades médias de todos os trajetos realizados, por modo.

\begin{tabular}{|c|c|c|c|c|c|c|c|c|c|c|c|}
\hline \multicolumn{3}{|c|}{ AUTOMÓVEL } & \multicolumn{4}{c|}{ MICRO-ÔNIBUS } & \multicolumn{3}{c|}{ ÔNIBUS } \\
\hline IDA & VOLTA & $\%$ & $\begin{array}{c}\text { Desvio } \\
\text { Padrão }\end{array}$ & IDA & VOLTA & $\%$ & $\begin{array}{c}\text { Desvio } \\
\text { Padrão }\end{array}$ & IDA & VOLTA & $\%$ & $\begin{array}{c}\text { Desvio } \\
\text { Padrão }\end{array}$ \\
\hline 15,5 & 25,1 & 61,9 & 6,7 & 14,1 & 21,9 & 55,3 & 5,5 & 11,7 & 21,5 & 83,8 & 6,9 \\
\hline
\end{tabular}

Como é possível observar, a diferença de desempenho é significativa para os três modos pesquisados. O desempenho das viagens de retorno ao centro é bastante superior ao sentido bairro, com destaque para os ônibus: $83,8 \%$ em relação às viagens de ida. 
A partir da velocidade média de cada um dos percursos e por cada modo utilizado foi calculado a média geral por sentido. Nas viagens com destino aos bairros a velocidade média foi de $13,7 \mathrm{~km} / \mathrm{h}$; já no sentido do centro o resultado foi $23,1 \mathrm{~km} / \mathrm{h}$. A média geral no sentido bairro e no sentido centro foram utilizadas para encontrar a média geral de todas as viagens realizadas. O Resultado foi de $18,4 \mathrm{~km} / \mathrm{h}$.

Sabe-se que o transporte coletivo opera sobre rotas fixas ou itinerários previamente determinados - as linhas de ônibus. Em função disso, mesmo que certos trechos estejam congestionados, os motoristas não podem buscar vias alternativas para escapar dos mesmos, restando aos usuários cativos desse sistema apenas a boa vontade de esperar. Espera-se que o mesmo não aconteça com os usuários de automóveis, visto que estes têm a liberdade de escolher as vias pelas quais trafegar. Assim, em situações de lentidão e congestionamentos do trânsito, é de se esperar que os motoristas de veículos particulares e táxi buscarem rotas alternativas, o que deve fazer grande diferença no tempo total dedicado às viagens urbanas.

Assim, uma das hipóteses que alimentou este trabalho admitia que o trajeto percorrido principalmente pelo automóvel fosse diferir bastante dos demais modos, tentando fugir dos trechos de vias congestionadas. No entanto, os resultados mostraram que boa parte dos trajetos foram comuns para os três modos, ou seja: apesar da liberdade para escolher o próprio itinerário, os motoristas de automóveis não tem muito para onde fugir. A pesquisa permitiu constatar também que, apesar de menor, o automóvel e o microônibus nem sempre conseguiu vencer as distâncias em menor tempo que o ônibus convencional. Isto se deve ao fato de Manaus dispor de poucas vias arteriais, várias delas únicas por vários quilômetros. Isto ajuda a explicar os congestionamentos de trânsito, comuns nos dias de hoje.

Os resultados mostraram grandes variações de desempenho dos três modos de transporte pesquisados. Nota-se que, apesar da origem e destino serem comuns, aos três modos, o microônibus e principalmente o automóvel buscou rotas alternativas para desviar-se de trechos de vias congestionadas. Mas, ao contrário do que esperam os motoristas, estas rotas alternativas nem sempre resultaram em melhor desempenho, anulado quase sempre pelo aumento da distância percorrida. 
Os dados da pesquisa mostraram que há uma relação direta entre a extensão das viagens e a velocidade média alcançada, de tal modo que quanto maior extensão, maior a velocidade média. Isto pode ser observado através dos gráficos das figuras 3a, $3 b$ e 3c, respectivamente ônibus, micro-ônibus e automóvel. Registre-se também que os dados de GPS mostraram que os piores trechos estão na área central, com veículos se deslocando e velocidade pouco superior à de uma caminhada a pé.

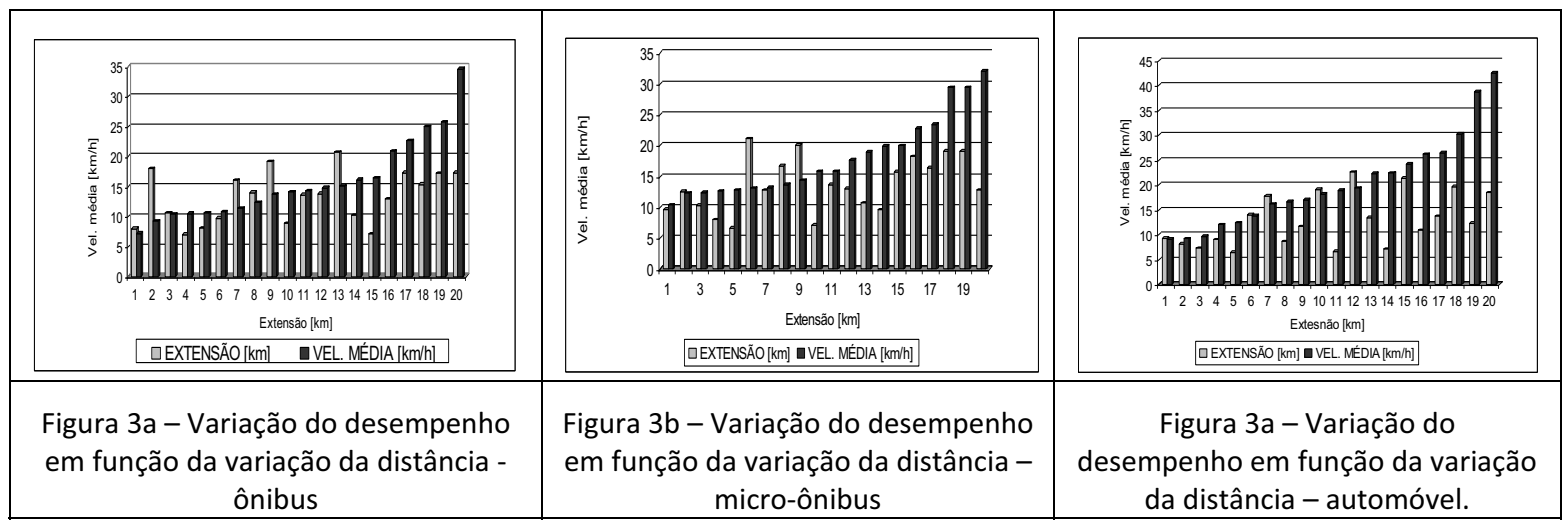

Outro aspecto importante que afeta principalmente os usuários de transporte coletivo está relacionado com itinerário das linhas de ônibus e micro-ônibus. Além de não poder alterar a rota para desviar de trechos congestionados, a estes veículos de transporte urbano têm sido impostos itinerários que levam os usuários em direção contrária ao seu destino final. Um bom exemplo disso é o trajeto percorrido pelos ônibus que passam pelo centro de Manaus. A maioria deles chega pela avenida Epaminondas e para retorna e retorna pela Getúlio Vargas. Houve trajeto em que o tempo gasto neste trecho correspondeu a mais de $30 \%$ da duração da viagem. A figura 04 ilustra esta descrição. 
Figura 04 - Quilometragem percorrida desnecessariamente pelos usuários de transporte público coletivo no centro de Manaus Fonte: Base Cartográfica da PMM, 2009; SMTU, 2011.

Organização: Aline Leite, 2012.

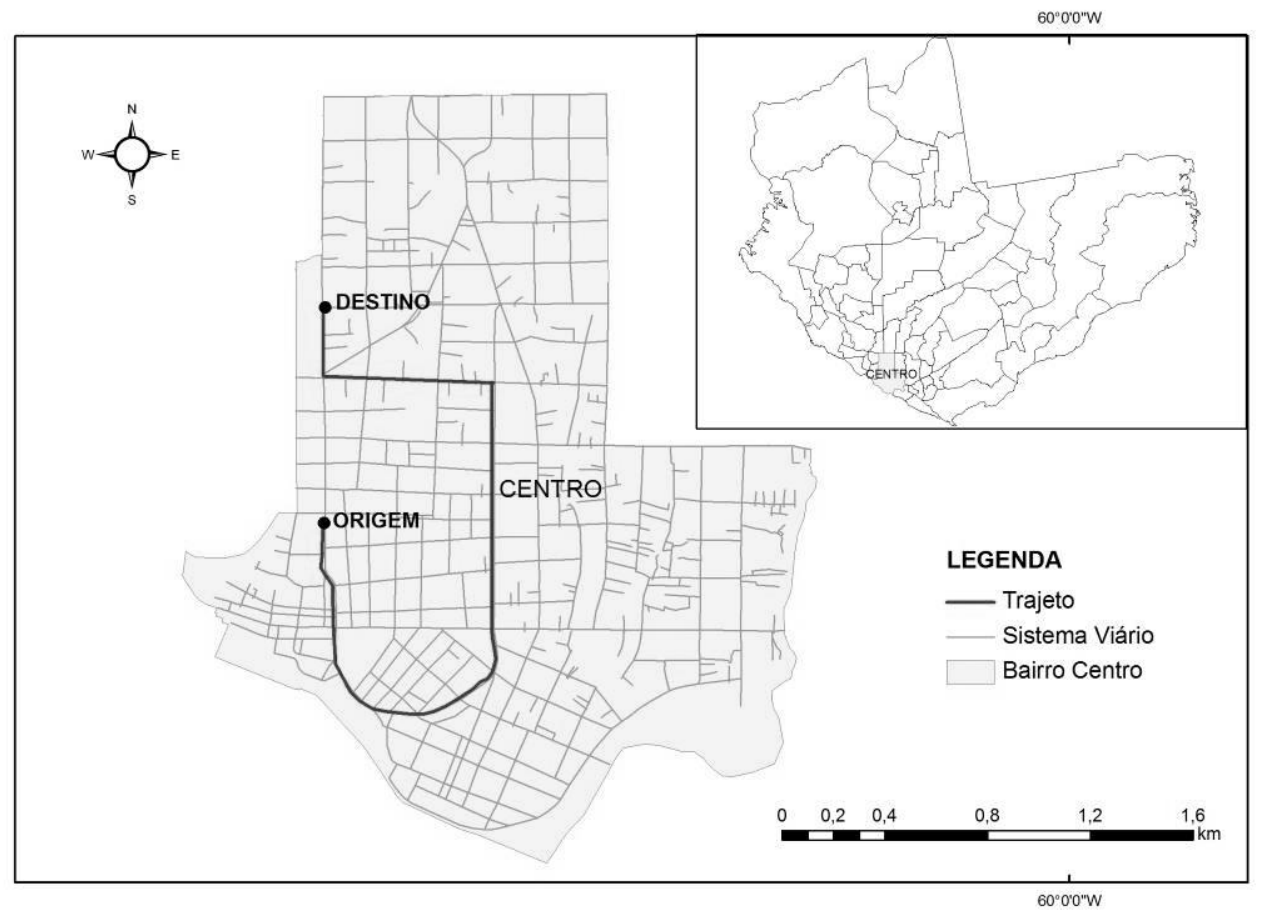

Os piores e os melhores trechos de cada viagem realizada foram identificados e mapeados, podendo concluir que o sistema viário exerce influencia sobre a duração das viagens sob dois aspetos diferentes: a) nas áreas mais centrais foram registrada lentidão em vias arteriais onde é comum a ocorrência de congestionamento de trânsito no final do dia e; b) no interior de bairros mais afastados, nas vias de acesso local de bairros que não planejados a circulação é dificultada pela inadequação das vias: estreitas, sinuosas, péssima qualidade das vias pavimentadas.

\section{Conclusões}

Em função de tamanho, é de se esperar que o automóvel apresente melhor desempenho que o microônibus e este, por sua vez, melhor que dos ônibus convencionais. No entanto, os dados mostraram que nem sempre ocorre desta maneira. Além de aumentar a distância a ser percorrida o motorista do veículo particular pode enfrentar outros trechos congestionados e comprometer 0 desempenho final da viagem. 
Além de serem menores, em função de concorrerem com o sistema de transporte coletivo convencional, os motoristas dos micros assumem comportamento mais agressivo no trânsito na tentativa de aumentar as vantagens comparativas em relação ao sistema convencional e deste modo aumentar o interesse dos passageiros por este serviço. Outro aspeto importante é o fato de que o tempo consumido por usuários para subir e descer dos ônibus é maior que dos micro-ônibus. Já os carros não precisam parar para este fim.

Considera-se (por tudo o que o trabalho permitiu concluir), que a metodologia adotada mostrou-se bastante consistente para o reconhecimento da variação de desempenho de modos de transporte de passageiros urbanos. Além de registrar os itinerários percorridos, pode-se reconhecer trechos das vias onde a velocidade média foi bastante reduzida. O reconhecimento destes trechos pode contribuir para identificar que fatores contribuem para o baixo desempenho nos mesmos. É forçoso reconhecer, por outro lado que, por maior que seja os transtornos que enfrentam os usuários do automóvel particular, estes estão bem abaixo daqueles enfrentados pelos usuários do transporte coletivo.

\section{Agradecimentos}

Agradecemos ao Conselho Nacional de Desenvolvimento Científico e Tecnológico (CNPq), que possibilitou a realização desta pesquisa por meio do financiamento da mesma. Ao Núcleo de Estudos e Pesquisas das Cidades na Amazônia Brasileira (NEPECAB) que financiaram os valores relativos ao modo carro (táxi) através do projeto financiado pelo CNPq Edital MCT/CNPq/CT-Amazônia $n^{\circ}$ 055/2008 (Processo n575517-2008-5) cujo título é: As transformações na rede urbana na Amazônia ocidental: Análise da influência do Pólo Industrial de Manaus na fronteira norte Amazonas - Roraima coordenado pelo Professor Doutor José Aldemir de Oliveira. 


\section{Referências bibliográficas}

Araújo, E. S. (2009). Desenvolvimento urbano local: o caso da Zona Franca de Manaus. Revista brasileira de Gestão Urbana, 1(1), 33-42.

Brasil (2010). Censos demográficos de 2010. Instituto Brasileiro de Geografia e Estatísticas - IBGE.

Goto, M. (2000). Uma análise de acessibilidade sob a ótica da equidade - O caso da região metropolitana de Belém. Dissertação (Mestrado) em Engenharia Civil - Área de concentração: Transportes. Universidade de São Paulo, Escola de Engenharia de São Carlos.

Leite, A. D. and G. A. de Souza (2011). Análise do tempo de deslocamento de operários do Pólo Industrial de Manaus, Amazonas. In Anais do $10^{\circ}$ Congreso Colombiano de Ingeniería de Tránsito y Transporte, Medelín, 5-7 Dezembro.

Manaus (1975). Plano de Desenvolvimento Local e Integrado - PDLI. Lei municipal n. 1213, de 02 de maio.

Manaus (2002) Lei Orgânica do Município - LOMAM. Prefeitura Municipal de Manaus.

Moura, L. K. F., J. A. Oliveira and J. A. Alves (2010). A Produção Do Espaço Urbano Na Amazônia: As Políticas Públicas Habitacionais No Período De 1980-2008 Em Manaus AM (BR). In Anais do $4^{\circ}$ Congresso Luso-Brasileiro para o planejamento urbano, regional, integrado, sustentável. Portugal. Disponível em: http://pluris2010.civil.uminho.pt/congresso_actas_ID.html

Nogueira, A. C. F., F. Sanson and e K. Pessoa (2007). A expansão urbana e demográfica da cidade de Manaus e seus impactos ambientais. In Anais XIII Simpósio Brasileiro de Sensoriamento Remoto, Florianópolis, Brasil, INPE, 5427- 5434.

Oliveira, J. P. (2002). Manaus: Plano Diretor e Expansão Urbana. Dissertação de Mestrado em Sociedade e Cultura da Amazônia. Programa de Pós- Graduação em Sociedade e Cultura na Amazônia, Universidade Federal do Amazonas.

Souza, G. A. de (2010). Transporte público a preço único: reforçando as desigualdades sociais. In Anais do $4^{\circ}$ Congresso Luso-Brasileiro para o planejamento urbano, regional, 
integrado, sustentável. Portugal. Disponível em: http://pluris2010.civil.uminho.pt/congresso actas ID.html

Taco, P. W.G., P. C. M. da Silva and Kneib, E. C. (2008). Escalas de Análise em Transportes de um índice de Acessibilidade Espacial: Caso de Estudo Aplicado a um Município Brasileiro. Anais do XXIV Congresso de Pesquisa e Ensino em Transportes, Fortaleza, 3-9 de novembro.

Zmitrowicz, W. and G. de A. Neto (1997). Infra-Estrutura Urbana. Texto técnico, Escola Politécnica da USP Departamento de Engenharia de Construção Civil, São Paulo. 